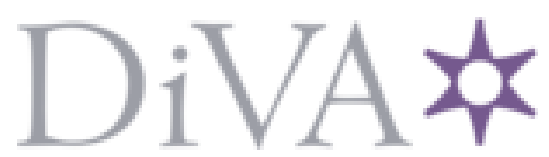

http://www.diva-portal.org

This is the published version of a paper published in American Journal of Physiology - Gastrointestinal and Liver Physiology.

Citation for the original published paper (version of record):

Schoultz, I., McKay, C., Graepel, R., Phan, V., Wang, A. et al. (2012)

Indomethacin-induced translocation of bacteria across enteric epithelia is reactive oxygen species-dependent and reduced by vitamin C.

American Journal of Physiology - Gastrointestinal and Liver Physiology, 303(5): G536-G545

http://dx.doi.org/10.1152/ajpgi.00125.2012

Access to the published version may require subscription.

N.B. When citing this work, cite the original published paper.

Permanent link to this version:

http://urn.kb.se/resolve?urn=urn:nbn:se:oru:diva-40007 


\title{
Indomethacin-induced translocation of bacteria across enteric epithelia is reactive oxygen species-dependent and reduced by vitamin $\mathrm{C}$
}

\author{
Ida Schoultz, ${ }^{1}$ Catherine M. McKay, ${ }^{1}$ Rabea Graepel, ${ }^{1}$ Van C. Phan, ${ }^{1}$ Arthur Wang, ${ }^{1}$ Johan Söderholm, ${ }^{2}$ \\ and Derek M. McKay ${ }^{1}$ \\ ${ }^{1}$ Gastrointestinal Research Group, Department of Physiology and Pharmacology, The Calvin, Phoebe, and Joan Snyder \\ Institute for Chronic Diseases, University of Calgary, Calgary, Alberta, Canada; and ${ }^{2}$ Department \\ of Clinical and Experimental Medicine, Linköping University, Linköping, Sweden
}

Submitted 22 March 2012; accepted in final form 7 June 2012

\begin{abstract}
Schoultz I, McKay CM, Graepel R, Phan VC, Wang A, Söderholm J, McKay DM. Indomethacin-induced translocation of bacteria across enteric epithelia is reactive oxygen species-dependent and reduced by vitamin C. Am J Physiol Gastrointest Liver Physiol 303: G536-G545, 2012. First published June 14, 2012; doi:10.1152/ajpgi.00125.2012.-The enteric epithelium must absorb nutrients and water and act as a barrier to the entry of luminal material into the body; this barrier function is a key component of innate immunity. Nonsteroidal anti-inflammatory drug (NSAID)-induced enteropathy occurs via inhibition of prostaglandin synthesis and perturbed epithelial mitochondrial activity. Here, the direct effect of NSAIDs [indomethacin, piroxicam (cyclooxygenase 1 and 2 inhibitors), and SC-560 (a cyclooxygenase 1 inhibitor)] on the barrier function of human T84 epithelial cell line monolayers was assessed by transepithelial electrical resistance (TER) and internalization and translocation of a commensal Escherichia coli. Exposure to $E$. coli in the presence and absence of drugs for $16 \mathrm{~h}$ reduced TER; however, monolayers cotreated with $E$. coli and indomethacin, but not piroxicam or SC-560, displayed significant increases in internalization and translocation of the bacteria. This was accompanied by increased reactive oxygen species (ROS) production, which was also increased in epithelia treated with $E$. coli only. Colocalization revealed upregulation of superoxide synthesis by mitochondria in epithelia treated with E. coli + indomethacin. Addition of antioxidants (vitamin $\mathrm{C}$ or a green tea polyphenol, epigallocathechin gallate) quenched the ROS and prevented the increase in E. coli internalization and translocation evoked by indomethacin, but not the drop in TER. Evidence of increased apoptosis was not observed in this model. The data implicate epithelial-derived ROS in indomethacin-induced barrier dysfunction and show that a portion of the bacteria likely cross the epithelium via a transcellular pathway. We speculate that addition of antioxidants as dietary supplements to NSAID treatment regimens would reduce the magnitude of decreased barrier function, specifically the transepithelial passage of bacteria.
\end{abstract}

permeability; nonsteroidal anti-inflammatory drug; mitochondria; intestine

THE INTESTINAL EPITHELIUM is the major interface with the external environment, tasked with the seemingly paradoxical roles of absorbing nutrients and water while restricting the free movement of luminal material into the underlying mucosa. The single layer of epithelial cells that line the gastrointestinal tract must keep the commensal microbiota at bay, which, despite providing many benefits for their host $(10,12,13)$, are a source of danger signals and triggers of pathophysiological events (1). While controversy exists as to whether increases in epithelial permeability are a cause or a consequence of intestinal disease,

Address for reprint requests and other correspondence: D. M. McKay, Dept. Physiology \& Pharmacology, 1877 HSC, Univ. of Calgary, 3330 Hospital Dr. NW, Calgary, AB, Canada T2N 4N1 (e-mail: dmckay@ucalgary.ca). there is little doubt that reduced epithelial integrity, whether due to frank ulceration or more subtle increases in paracellular or transcellular permeation, can promote inflammation (38). Nonsteroidal anti-inflammatory drugs (NSAIDs), such as indomethacin and piroxicam, are associated with significant gastrointestinal side effects, particularly bleeding, gastric mucosal erosions and ulcers, and increased small bowel permeability $(15,36)$. The exact mechanism behind the NSAIDinduced barrier dysfunction is not completely understood. The loss of cytoprotection due to NSAID-induced inhibition of cyclooxygenase (COX) activity and, hence, prostaglandin synthesis is certainly one component of NSAID-induced enteropathy $(16,43,47)$. Studies have also linked indomethacininduced gastropathy to mitochondrial damage and dysfunction and, consequently, oxidative stress and apoptosis of gastric mucosal cells $(19,26,43,45)$. Similarly, intestinal lesions elicited by indomethacin can be accompanied by swollen and irregular mitochondria in the epithelium, cardinal signs of mitochondrial damage and oxidative stress (4). Other stimuli, such as infection and inflammation, can evoke increases in epithelial permeability, and each has been shown to elicit some degree of mitochondrial damage in the epithelium (3, $5,8)$. Thus we recently posited that metabolic stress in the enterocyte could be a common denominator in inflammatory bowel disease, which may be of particular relevance in disease relapse (40).

NSAID treatment can increase intestinal permeability in patients suffering from Crohn's disease (28, 42, 51). These studies used small-molecular-weight probes that typically enter the mucosa via the paracellular permeation pathway. Given the association between the commensal flora, decreased epithelial barrier function, and intestinal inflammation (1), the following issue arises: Does NSAID treatment enhance commensal bacteria crossing of the epithelium? If so, by what route do the bacteria cross the epithelium and do reactive oxygen species (ROS), a product of oxidative stress, participate in this event? Also, if ROS are involved in NSAID-induced increases in epithelial permeability, would antioxidant agents, added as nutritional supplements, block the barrier dysfunction?

Monolayers of the human T84 crypt-like colonic epithelial cell line have been widely used as an in vitro model system to assess the regulation of epithelial permeability $(14,24)$. Using this model, we found that indomethacin, but not piroxicam [both of which inhibit COX-1 and -2 activity (49)], increased epithelial internalization and translocation of nonpathogenic, noninvasive Escherichia coli. This effect of indomethacin was accompanied by prolonged production of ROS, and cotreatment with vitamin $\mathrm{C}$ [or epigallocathechin gallate (EGCG), a 
green tea polyphenol] quenched the ROS and significantly reduced the epithelial barrier defect. These findings suggest that administration of antioxidants + indomethacin would ablate the increases in epithelial permeability while leaving the NSAID's COX-inhibitory/anti-inflammatory effect intact.

\section{MATERIALS AND METHODS}

\section{Cell Culture}

The human colon-derived crypt-like T84 cell line (passages 42 100; American Type Culture Collection, Manassas, VA) was cultured at $37^{\circ} \mathrm{C}$ in $5 \% \mathrm{CO}_{2}$ in a $1: 1$ mixture of Dulbecco's modified Eagle's medium and Ham's F-12 medium, supplemented with $2 \%$ penicillinstreptomycin, $1.5 \%$ HEPES, and 10\% FBS (41). To evaluate epithelial barrier function, $1 \times 10^{6}$ cells $/ \mathrm{ml}$ were seeded onto semipermeable filters $\left[3-\mu \mathrm{m}\right.$ pore size, $1.2-\mathrm{cm}^{2}$ surface area; Greiner Biosciences (VWR)] and cultured until transepithelial resistance (TER) was $>1,000 \Omega / \mathrm{cm}^{2}$ (which is considered confluent). Starting TER values in this study were $1,000-3,500 \Omega / \mathrm{cm}^{2}$. For immunoblotting and quantitative PCR analyses, cells were seeded at a density of $5 \times$ $10^{5}$ cells/well in 12-well plastic cell culture plates and used at $\sim 70 \%$ confluence, as determined by phase-contrast microscopy.

\section{Chemicals and Bacteria}

Indomethacin and piroxicam [which have similar, but not identical, $\mathrm{IC}_{50}$ for $\mathrm{COX}$ inhibition $\left.(34,49)\right]$ and SC-560 (all at $\left.1 \mu \mathrm{M}\right)(24)$, vitamin C $(0.25 \mathrm{mM})$, and the green tea extract EGCG $(100 \mu \mathrm{M}$; Sigma Chemical, St. Louis, MO) were added alone or in combination to the apical side of filter-grown epithelial monolayers. E. coli (strain HB101) was grown and cultured overnight in an orbital shaker in Luria-Bertani (LB) broth at $37^{\circ} \mathrm{C}$ and added to the apical surface of confluent monolayers at a final concentration of $10^{6}$ colony-forming units $(\mathrm{cfu}) / \mathrm{ml}(23,30,31,41)$. A putative toxic effect of all drugs on the $E$. coli was evaluated in 24-h bacterial growth curves, with optical density and agar plate colony growth used to evaluate bacterial cell numbers.

\section{Assessing Metabolic Stress}

Epithelial mitochondrial activity. T84 cells $\left(10^{5}\right)$ were seeded in 96-well plates, cultured until $\sim 70 \%$ confluent, and exposed to indomethacin, piroxicam, or SC-560 for $16 \mathrm{~h}$. Mitochondrial activity was evaluated following treatment by measurement of the mitochondrialdependent reduction of colorless 3-(4,5-dimethylthiazol-2-yl)-2,5diphenyltetrazolium bromide (MTT) to a blue formazan. Briefly, cells were washed with phenol red-free RPMI medium, supplemented with FBS $(10 \%)$ and HEPES $(36 \mu \mathrm{M})$, and incubated with MTT $(100 \mu \mathrm{M})$ for $4 \mathrm{~h}$ at $37^{\circ} \mathrm{C}$. The reaction was stopped by the addition of $50 \mu \mathrm{l}$ of acidic isopropanol, and absorbance was measured at $595 \mathrm{~nm}$. Results are expressed in arbitrary units.

Assessment of mRNA for mitochondria-associated enzymes. Gene expression of ATP synthase, peroxiredoxin 3, and NADH coenzyme $\mathrm{Q}$ reductase following $16 \mathrm{~h}$ of exposure to $E$. coli in the presence or absence of indomethacin was assessed by real-time PCR. Total RNA was extracted from T84 cells following the standard protocol of the PureLink RNA Mini Kit (Invitrogen), and cDNA was reverse-transcribed from $0.5 \mu \mathrm{g}$ of RNA with the iScript cDNA Synthesis Kit (Bio-Rad, Mississauga, ON, Canada). Real-time PCRs were set up using concentrations from a standard protocol for iQ SYBR Green Supermix. Briefly, each cDNA sample was incubated in a $20-\mu 1$ reaction containing $1 \mu \mathrm{l}$ of cDNA, $300 \mu \mathrm{M}$ nucleotide primers, and $10 \mu \mathrm{l}$ of $2 \times$ iQ SYBR Green Supermix. All samples underwent PCR under the following conditions: an initial activation step at $95^{\circ} \mathrm{C}$ for 2 min followed by a 15 -s denaturing step at $95^{\circ} \mathrm{C}$, an annealing step at $55^{\circ} \mathrm{C}$ for $15 \mathrm{~s}$, and an extension step at $68^{\circ} \mathrm{C}$ for $20 \mathrm{~s}$. Forty cycles were completed and followed by a melting curve analysis. Relative expression was calculated by determination of the difference between the housekeeping gene 18S rRNA and the expression of the gene of interest. Results are expressed as fold difference compared with untreated monolayers (control). All primers were designed using the Primer3 program (http://frodo.wi.mit.edu/cgi-bin/primer3/primer3). The following primers were used: GCAGATTTTGGCAGGTGAAT (forward) and AGGGGCAAGGAGAGAGACA (reverse) for ATP synthase (GenBank no. NM_001686.3), AGGACGGTTGCTCCGAGCGT (forward) and GGTGCATGGCATGAGGAACTGGTG (reverse) for peroxiredoxin 3 (GenBank no. NM_006793), CCACCATCAACTACCCGTTC (forward) and AAGCCGCAGTAGATGCACTT (reverse) for NADH coenzyme Q reductase (GenBank no. NM_002496.3), and ATACATGCCGAAGGGCGCTG (forward) and AGGGGCTGACCGGGTTGGTT (reverse) for 18S rRNA (GenBank no. NR_003286.2).

Detection of ROS. The production of ROS was determined using the cell-permeable detection reagent chloromethyl $2^{\prime}, 7^{\prime}$-dichlorofluorescein diacetate $\left(\mathrm{CM}-\mathrm{H}_{2} \mathrm{DCFDA}\right.$; excitation at $488 \mathrm{~nm}$, emission at $530 \mathrm{~nm}$; Invitrogen $)$. T84 cells $\left(2 \times 10^{5}\right.$ cells $)$ were seeded onto glass coverslips and cultured until $\sim 30 \%$ confluent in 12-well plates. After $6 \mathrm{~h}$ of exposure to NSAID in the presence or absence of E. coli, the cells were rinsed twice in $37^{\circ} \mathrm{C}$ PBS and incubated with $10 \mu \mathrm{M}$ $\mathrm{CM}-\mathrm{H}_{2} \mathrm{DCFDA}$ for $30 \mathrm{~min}$ at $37^{\circ} \mathrm{C}$ in the dark. After three quick rinses in PBS, coverslips were fixed in fresh 4\% PFA for $5 \mathrm{~min}$ and washed in PBS three times for 2 min each. Epithelia were then treated with the nuclear stain 4',6-diamidino-2-phenylindole (DAPI, $0.2 \mu \mathrm{g} /$ $\mathrm{ml}$ ) for $5 \mathrm{~min}$ at room temperature in the dark. Coverslips were rinsed 3 times in PBS and mounted on slides using the Fluorosave reagent (Calbiochem) and stored in the dark at $4^{\circ} \mathrm{C}$ prior to examination. Coded slides were assessed in a blinded fashion for the degree and pattern of fluorescence on an Olympus BX41 microscope using a standard filter for green fluorescence and a UV-light filter for detection of DAPI with a $\times 40$ objective. Images were captured using QCapture software (Olympus Canada, Mississauga, ON, Canada). Identical conditions and exposure times were used in each experiment and set to avoid overexposure of the $\mathrm{CM}-\mathrm{H}_{2}$ DCFDA and DAPI fluorescence. Random areas for quantification were chosen based on DAPI staining, and ROS-induced fluorescence was evaluated in a quantitative manner. Six images were acquired from each individual monolayer, performed in triplicates in each experiment, giving a total number of 18 images analyzed per treatment in each experiment. Mean fluorescence intensity of CM- ${ }_{2}$ DCFDA (dichlorodihydrofluorescein) was normalized to the mean fluorescence intensity of the DAPI nuclear stain in each image, as previously described (27). Background fluorescence was accounted for and subtracted from the mean fluorescence intensity of each stain.

Labeling of mitochondria and detection of mitochondrial superoxide. Mitochondria were visualized using the fluorescent dye MitoTracker Green (Invitrogen; excitation at $490 \mathrm{~nm}$, emission at $516 \mathrm{~nm}$ ). For specific analysis of mitochondrial production of superoxide, the cellpermeable MitoSOX Red reagent was used (Invitrogen). MitoSOX Red selectively targets mitochondria and fluoresces when rapidly oxidized by superoxide (excitation at $510 \mathrm{~nm}$, emission at $580 \mathrm{~nm}$ ). T84 cells $\left(2 \times 10^{5}\right.$ cells $)$ were seeded onto glass coverslips and cultured until $\sim 30 \%$ confluent in 12-well plates. After 6 and $16 \mathrm{~h}$ of exposure to NSAID in the presence and absence of $E$. coli, the cells were washed twice in PBS and coincubated with $5 \mu \mathrm{M}$ MitoSOX Red, $200 \mathrm{nM}$ MitoTracker Green, and $0.2 \mu \mathrm{g} / \mathrm{ml}$ DAPI for $30 \mathrm{~min}$ at $37^{\circ} \mathrm{C}$ in the dark. After two 5-min washes in HBSS, the coverslips were fixed in 4\% PFA for $15 \mathrm{~min}$ at room temperature and, again, subjected to two 5-min washes in HBSS. Coverslips were mounted on slides and stored in the dark at $4{ }^{\circ} \mathrm{C}$ prior to examination. The degree and pattern of fluorescence were determined using an Olympus BX41 microscope. Images were captured using a $\times 60$ objective and QCapture software. Identical conditions and exposure times were used in each experiment and set to avoid overexposure of the MitoSOX Red, MitoTracker Green, and DAPI fluorescence. In additional experi- 
ments, $\sim 5-\mathrm{mm}^{2}$ pieces of murine duodenum were placed into 12 -well plates in culture medium in the presence or absence of indomethacin $(1 \mu \mathrm{M})$. After $6 \mathrm{~h}$, tissues were washed twice in PBS and incubated with MitoSOX Red, MitoTracker Green, and DAPI for $30 \mathrm{~min}$ at $37^{\circ} \mathrm{C}$ in the dark. After two 5-min washes in HBSS, tissues were snap-frozen in optimal cutting temperature compound, and 7- $\mu \mathrm{m}$ cryosections were cut and mounted on coded slides. The degree of fluorescence was assessed in a blinded fashion, where a maximum of 3 points was allotted to reflect fluorescence intensity and 3 points to reflect distribution of the fluorescence, giving a maximum score of 6 .

\section{Monitoring Epithelial Barrier Function}

$T E R$. Changes in paracellular permeability were assessed by measuring TER across filter-grown T84 cell monolayers. TER was recorded at time 0 (the start of the experiment) and $16 \mathrm{~h}$ after treatment using a voltmeter and matched electrodes (Millicell-ERS, Millipore, Bedford, MA). Data are expressed as the percentage of the pretreatment TER value (41).

Bacterial translocation. Confluent filter-grown epithelial cell monolayers were transferred to antibiotic-free culture medium, and $E$. coli $\left(10^{6} \mathrm{cfu}\right)$ was added with or without drug treatments to the apical compartment of the culture well. After $16 \mathrm{~h}, 150-\mu \mathrm{l}$ aliquots of basolateral media were collected, and the presence of bacteria was determined by serial dilution in PBS and overnight culture $\left(37^{\circ} \mathrm{C}\right)$ on LB-agar plates followed by colony counting (41).

Bacterial internalization. T84 cells were seeded in 12-well plates; when they reached $\sim 70 \%$ confluence, the cells were incubated with $E$. coli $\left(10^{6} \mathrm{cfu}\right)$ with or without various drug regimens for $16 \mathrm{~h}$. A sample of culture medium was collected, and the extracellular concentration of bacteria was determined as described above. The remaining medium was aspirated, and cells were treated with gentamicin $(200 \mu \mathrm{g} / \mathrm{ml})$ for $45 \mathrm{~min}$. The epithelia were extensively washed with PBS and lysed with cold $1 \%$ Triton $\mathrm{X}-100$ for $1.5 \mathrm{~h}$ at $4^{\circ} \mathrm{C}$, and the number of viable internalized bacteria was determined and presented as colony-forming units per milliliter of total lysate (41).

In other experiments, after gentamicin treatment, the epithelia were rinsed extensively with PBS, placed in antibiotic-free medium, and cultured for 6 and $24 \mathrm{~h}$. Then aliquots of medium were collected and plated on LB-agar to determine if viable bacteria had been released from the epithelial layer (samples of culture medium were collected immediately after gentamicin withdrawal and cultured on agar, and no bacterial growth was found).

\section{Immunoblotting}

Standard immunoblotting protocols (41) were used to assess protein expression after treatment with $E$. coli $\mathrm{HB} 101\left(10^{6} \mathrm{cfu} / \mathrm{ml}\right)$ in the presence and absence of indomethacin. Briefly, T84 cells were lysed in 100-200 $\mu$ l of ice-cold lysis buffer [20 mM Tris ( $\mathrm{pH} 7.5), 150 \mathrm{mM}$ $\mathrm{NaCl}, 1$ mM EDTA, 1 mM EGTA, 1\% Triton X-100, 2.5 mM sodium pyrophosphate, $1 \mathrm{mM} \mathrm{NaVO}$, and complete EDTA-free protease inhibitor complex (Roche Diagnostics, Indianapolis, IN)], and extracts were sonicated for $10 \mathrm{~s}$ and cleared by centrifugation. After protein concentrations were determined by the Bio-Rad/Bradford assay, 15 $\mu \mathrm{g}$ of protein were mixed with Laemmli loading buffer and run on a SDS- $12 \%$ polyacrylamide gel $(100 \mathrm{~V}$ for $1 \mathrm{~h})$. The separated proteins were electroblotted to polyvinylidene difluoride membranes (VWR), blocked with Carnation 5\% nonfat milk for $1 \mathrm{~h}$ at room temperature, and incubated at $4{ }^{\circ} \mathrm{C}$ overnight with rabbit $\mathrm{IgG}$ antibodies against anti-cleaved caspase-3 (1:1,000 dilution) or anti-apoptosis-inducing factor (AIF, 1:1,000 dilution; both from Cell Signaling Technology, Beverly, MA). Membranes were washed extensively and incubated with goat anti-rabbit IgG (1:5,000 dilution; Santa Cruz Biotechnology, Santa Cruz, CA) for $1 \mathrm{~h}$ at room temperature. After the membranes were washed, immunoreactive proteins were visualized by enhanced chemiluminescence (Amersham Pharmacia, Piscataway, NJ) and exposed to Kodak XB film (Eastman Kodak, Rochester, NY).
For loading control, membranes were stripped twice in $2.5 \%$ acetic acid stripping buffer, reprobed with goat IgG against actin $(1: 1,000$ dilution; Santa Cruz Biotechnology), and developed.

\section{Data Presentation and Statistical Analysis}

Data for TER, bacterial internalization and translocation, and spectrophotometric analysis are presented as means $\pm \mathrm{SE}$; $n$ repre-

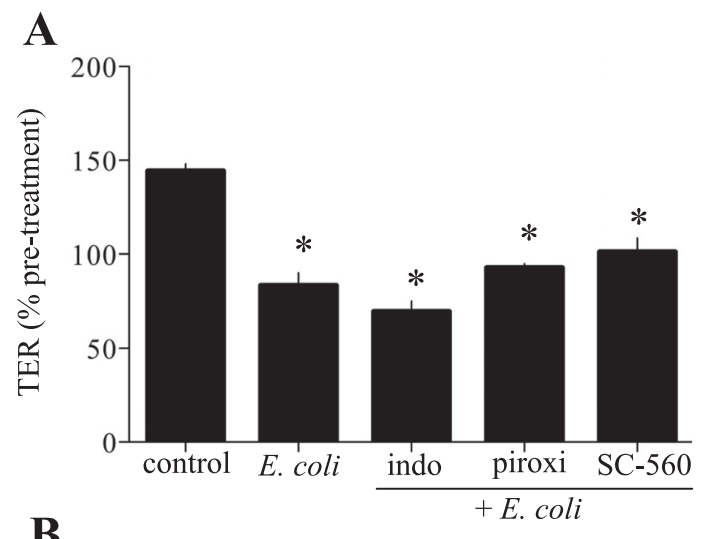

B
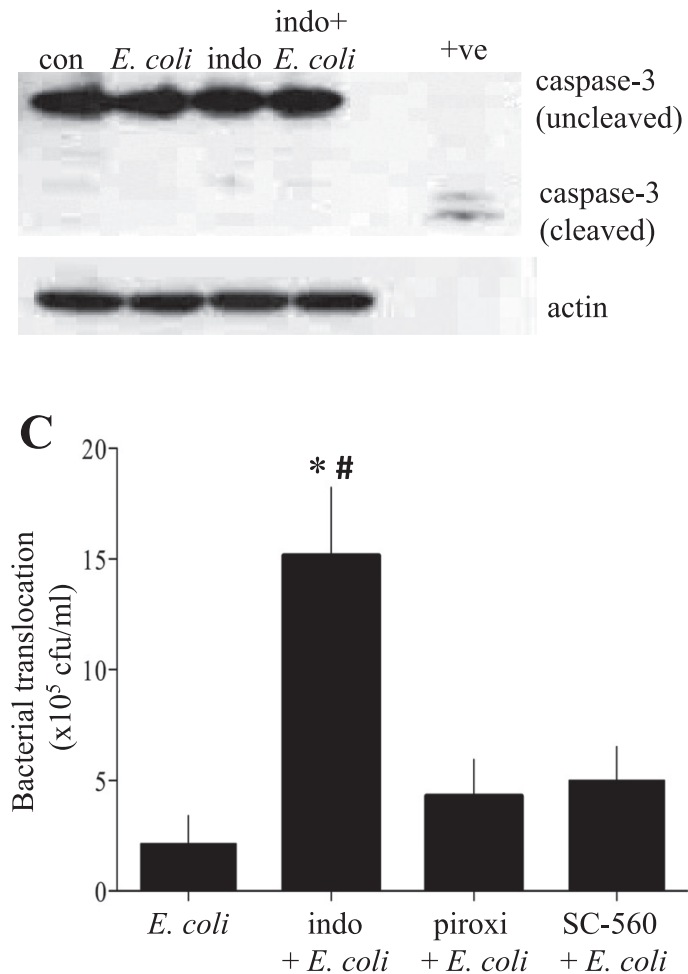

Fig. 1. Indomethacin induces increased T84 epithelial transcytosis of nonpathogenic Escherichia coli across T84 epithelial monolayers. A: while control monolayers showed an increase in transepithelial electrical resistance (TER) over a 16-h experimental period, monolayers treated with $E$. coli $\left(10^{6} \mathrm{cfu}\right)$ in the presence or absence of indomethacin (indo), piroxicam (piroxi), or SC-560 (all at $1 \mu \mathrm{M}$ ) displayed a drop in TER. Values are means \pm SE; $n=7$ monolayers from 3 experiments. $* P<0.001$ vs. control. $B$ : indomethacin did not induce apoptosis alone or in combination with $E$. coli, as indicated by lack of cleaved caspase-3. Staurosporine (+ve) was used as a positive control. Blots are representative of 2 independent experiments. $C$ : indomethacin caused a significant increase in transcytosis of the nonpathogenic, noninvasive E. coli strain HB101 across T84 monolayers compared with untreated (control) monolayers and monolayers treated with piroxicam or SC-560. cfu, Colonyforming units. Values are means $\pm \mathrm{SE} ; n=8$ epithelial monolayers from 2 experiments. $\# P<0.01$ vs. E. coli + piroxicam and E. coli + SC-560. 


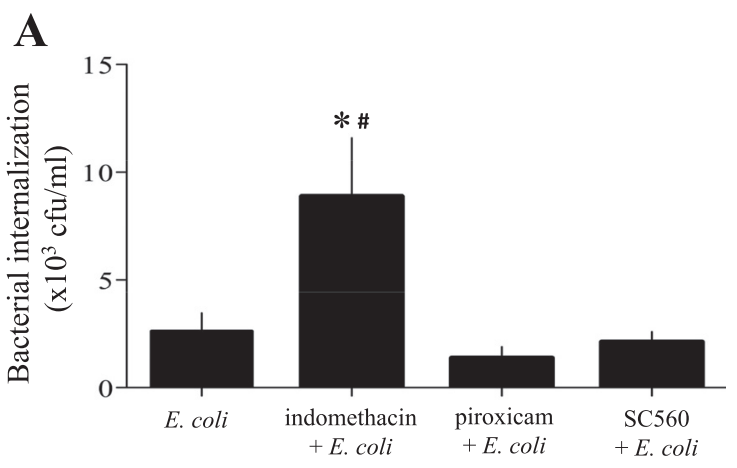

B

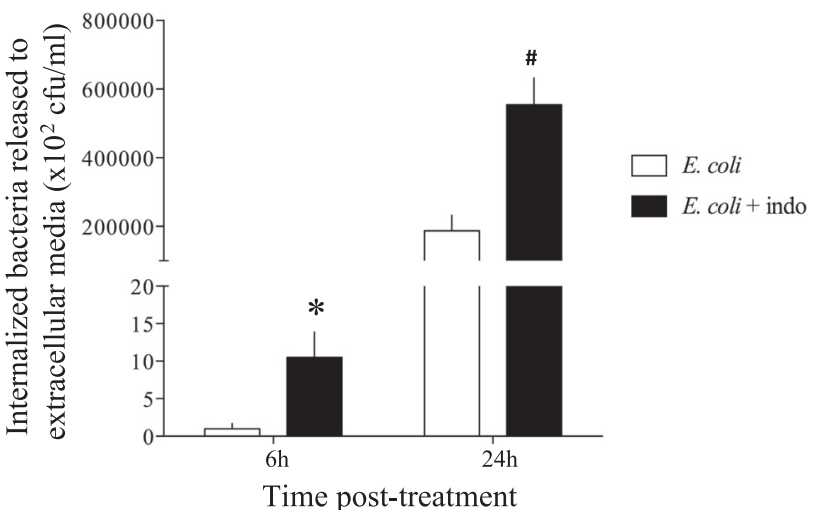

Fig. 2. Indomethacin induces increased T84 epithelial cell internalization of $E$. coli. A: indomethacin, but not piroxicam or SC-560 (all at $1 \mu \mathrm{M}$ ), induces a significant increase in internalization of nonpathogenic E. coli into T84 monolayers. Values are means $\pm \mathrm{SE} ; n=8$ epithelial monolayers from 2 experiments. ${ }^{*} P<0.05$ vs. $E$. coli alone. $\# P<0.01$ vs. $E$. coli + piroxicam. $B$ : internalized bacteria in monolayers treated with indomethacin "escaped" into the cell culture medium and were detectable by agar colony grown in samples taken 6 and $24 \mathrm{~h}$ after external bacteria were killed with gentamicin. Values are means \pm SE; $n=4$ epithelial preparations. $* P<0.05$ vs. E. coli at $6 \mathrm{~h} . \# P<0.01$ vs. E. coli alone at $24 \mathrm{~h}$ and $E$. coli + indomethacin at $6 \mathrm{~h}$.

sents the number of individual epithelial monolayers from a specified number of experiments. For statistical analysis, a one-way ANOVA was followed by a post hoc Tukey's test for pair-wise comparisons. Data generated from captured images of ROS-induced fluorescence were assessed by analysis of the mean fluorescence intensity of CM- $\mathrm{H}_{2}$ DCFDA (normalized to DAPI fluorescence) by Kruskal-Wallis one-way ANOVA. Data are presented as fold changes compared with nonstimulated control monolayers. A statistically significant difference was accepted at $P<0.05$.

\section{RESULTS}

\section{Indomethacin Enhances Bacterial Translocation and Internalization Across T84 Monolayers}

In comparison with previous studies (31), indomethacin induced a small decrease in TER (data not shown), while $E$. coli HB101 alone $\left(10^{6} \mathrm{cfu}\right)$ evoked a more marked significant decrease in TER at $16 \mathrm{~h}$ posttreatment (Fig. 1A) that was not enhanced by cotreatment with any of the COX inhibitors. A drop in TER could reflect an increase in epithelial cell death via apoptosis or necrosis. Analysis of caspase-3 cleavage (Fig. 1B) and release of AIF from mitochondria into the cytosol (data not shown) revealed no evidence of increased apoptosis under any of the experimental conditions. In contrast, treatment with indomethacin, but not piroxicam or SC-560, evoked a statistically significant increase in the translocation of $E$. coli across the monolayer (Fig. 1C), indicating a barrier defect that was not apparent when TER was used as the index of epithelial permeability.

Bacteria could cross the epithelium paracellularly, by passing between the tight junctions, or via a transcellular route. The gentamicin assay showed that cotreatment with indomethacin, but not piroxicam or SC-560, resulted in a significant increase in $E$. coli internalization (Fig. 2A). These data suggest that at least a portion of the bacteria that cross the epithelial monolayer do so via the transcellular pathway. Additional credence is given to this postulate by the finding that, following gentamicin treatment and substantive washes, E. coli that were internalized as a consequence of exposure to indomethacin were released or escaped from the enterocyte (Fig. 2B). The inability of piroxicam or SC-560 to reproduce the effects of indomethacin on bacterial internalization and transcytosis across epithelial monolayers suggests that the effect of the latter is independent of its ability to inhibit COX activity.

\section{A}

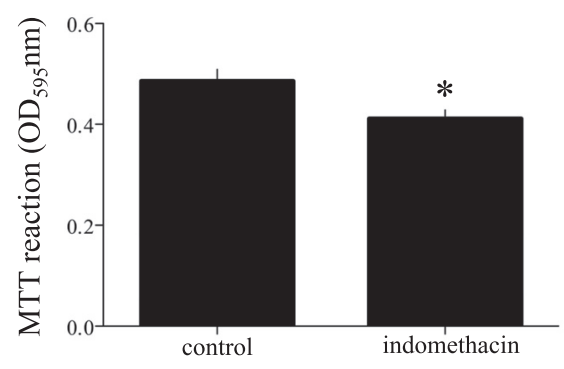

\section{B}

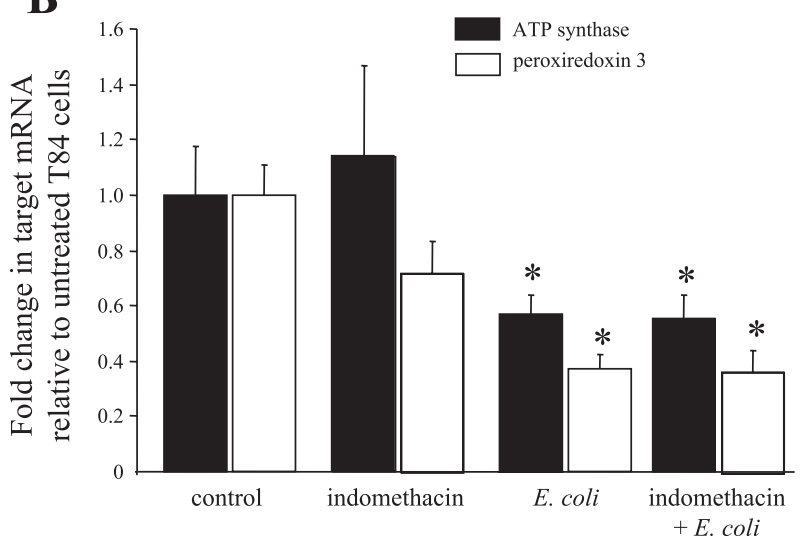

Fig. 3. Indomethacin reduces mitochondrial activity in $\mathrm{T} 84$ epithelial cells. A: exposure of T84 cells to indomethacin $(1 \mu \mathrm{M})$ results in a small, but statistically significant, reduction in mitochondrial activity $16 \mathrm{~h}$ posttreatment, as gauged by 3-(4,5-dimethylthiazol-2-yl)-2,5-diphenyltetrazolium bromide (MTT) cleavage. $\mathrm{OD}_{595 \mathrm{~nm}}$, optical density at $595 \mathrm{~nm}$. Values are means $\pm \mathrm{SE}$; $n=20$ epithelial preparations from 3 experiments. $* P<0.05$ vs. timematched control. $B$ : quantitative PCR analysis revealed significant reductions in mRNA for ATP synthase and the mitochondria-associated antioxidant peroxiredoxin-3 in monolayers treated with $E$. coli $\left(10^{6} \mathrm{cfu}\right)$ with or without indomethacin compared with untreated (control) monolayers. Values are means \pm SE; $n=6$ epithelial preparations, from 2 independent experiments. $* P<0.05$ vs. control. 


\section{Indomethacin Reduces Epithelial Mitochondrial Activity}

With the MTT assay used as an indirect measure of mitochondrial activity, indomethacin was found to directly perturb epithelial mitochondrial activity (Fig. 3A). In addition, quantitative PCR analysis revealed significant reductions in mRNA for ATP synthase and the mitochondria-associated antioxidant peroxiredoxin 3, but not NADH coenzyme Q reductase (data not shown), in epithelia treated with E. coli and E. coli + indomethacin (Fig. 3B).

\section{Indomethacin-Treated Epithelia Produce Increased Amounts of $R O S$}

Indomethacin is known to cause gastrointestinal lesions and induce increased production of ROS (26). Using this in vitro cell culture model and the ROS-activated fluorescent probe CM- $\mathrm{H}_{2}$ DCFDA, we observed increases in ROS in epithelial monolayers treated with E. coli, indomethacin, and E. coli + indomethacin at $6 \mathrm{~h}$ posttreatment (Fig. 4). Similar events were not found in piroxicam-treated epithelia. Specificity of the reaction was confirmed by addition of $\mathrm{H}_{2} \mathrm{O}_{2}$ as a positive control and quenching of the ROS by vitamin $\mathrm{C}$ (Fig. 4). This pattern of ROS production was similar, although reduced in magnitude, at $16 \mathrm{~h}$ posttreatment (data not shown). To evaluate the source and nature of the ROS, epithelia were stained with MitoTracker Green and MitoSOX Red. This approach confirmed that ROS were produced by epithelia exposed to indomethacin, E. coli, and E. coli + indomethacin and that mitochondria-derived superoxide was a component of these responses (Fig. 5). Furthermore, this imaging approach revealed that substantially more superoxide that colocalized to mitochondria was produced by T84 epithelia treated with E. coli + indomethacin than by T84 epithelia treated with E. coli or indomethacin alone at 6 and $16 \mathrm{~h}$ posttreatment (Fig. 5). In addition, short-term ex vivo culture of segments of murine duodenum revealed that $6 \mathrm{~h}$ of treatment with indomethacin resulted in increased mitochondria-generated superoxide, as demonstrated by MitoSOX Red fluorescence and semiquantitative analysis (Fig. 6).

\section{Vitamin C Blocks Indomethacin-Induced Increases in Bacterial Translocation and Internalization}

Positing that ROS activity contributed to the internalization and translocation of bacteria, we conducted studies with vitamin $\mathrm{C}$, a potent ROS scavenger, and the green tea extract
Fig. 4. Indomethacin induces reactive oxygen species (ROS) production by T84 epithelial cells. ROS production was determined $6 \mathrm{~h}$ after treatment using the chloromethyl $2^{\prime}, 7^{\prime}$ dichlorofluorescein diacetate (CM- $\mathrm{H}_{2}$ DCFDA) probe $(10 \mu \mathrm{M})$. T84 cells treated with E. coli $\left(10^{6} \mathrm{cfu}\right)$, indomethacin $(1 \mu \mathrm{M})$, or both showed increased ROS generation, which was quenched in the presence of vitamin $\mathrm{C}$ (vit $\mathrm{C}$; $0.25 \mathrm{mM}$ ). Effect of $0.5 \mathrm{mM} \mathrm{H}_{2} \mathrm{O}_{2}$ is included as a specificity control. Epithelial preparations are from 2 experiments and represent 30-36 images analyzed in total for each treatment group. DCF, dichlorodihydrofluorescein. Values are means \pm SE. $* P<0.05$ vs. control.
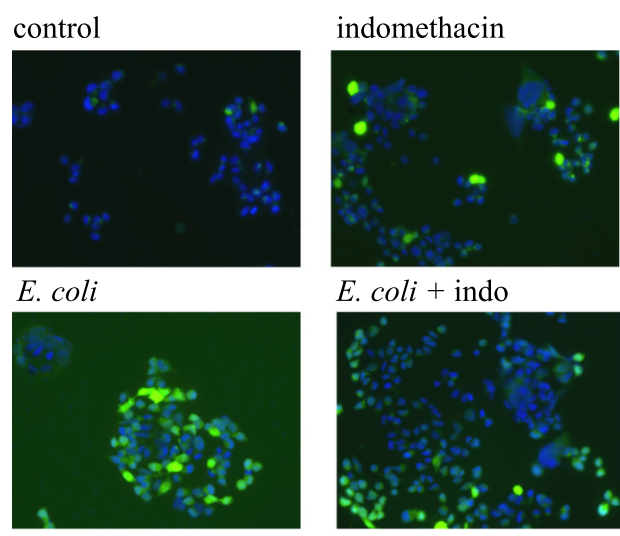

\section{E. coli + indo}
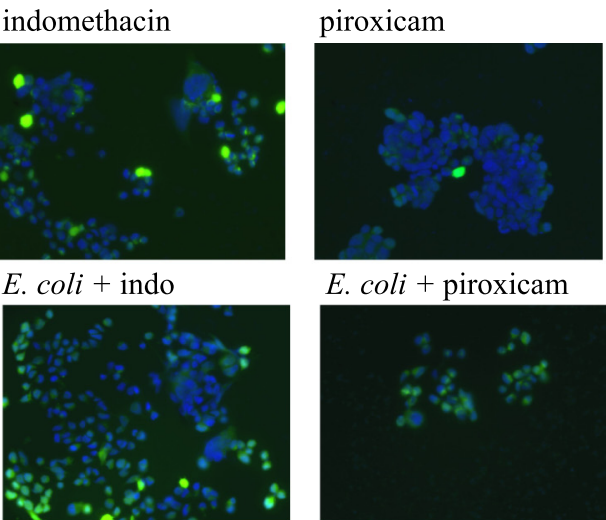

E. coli + piroxicam
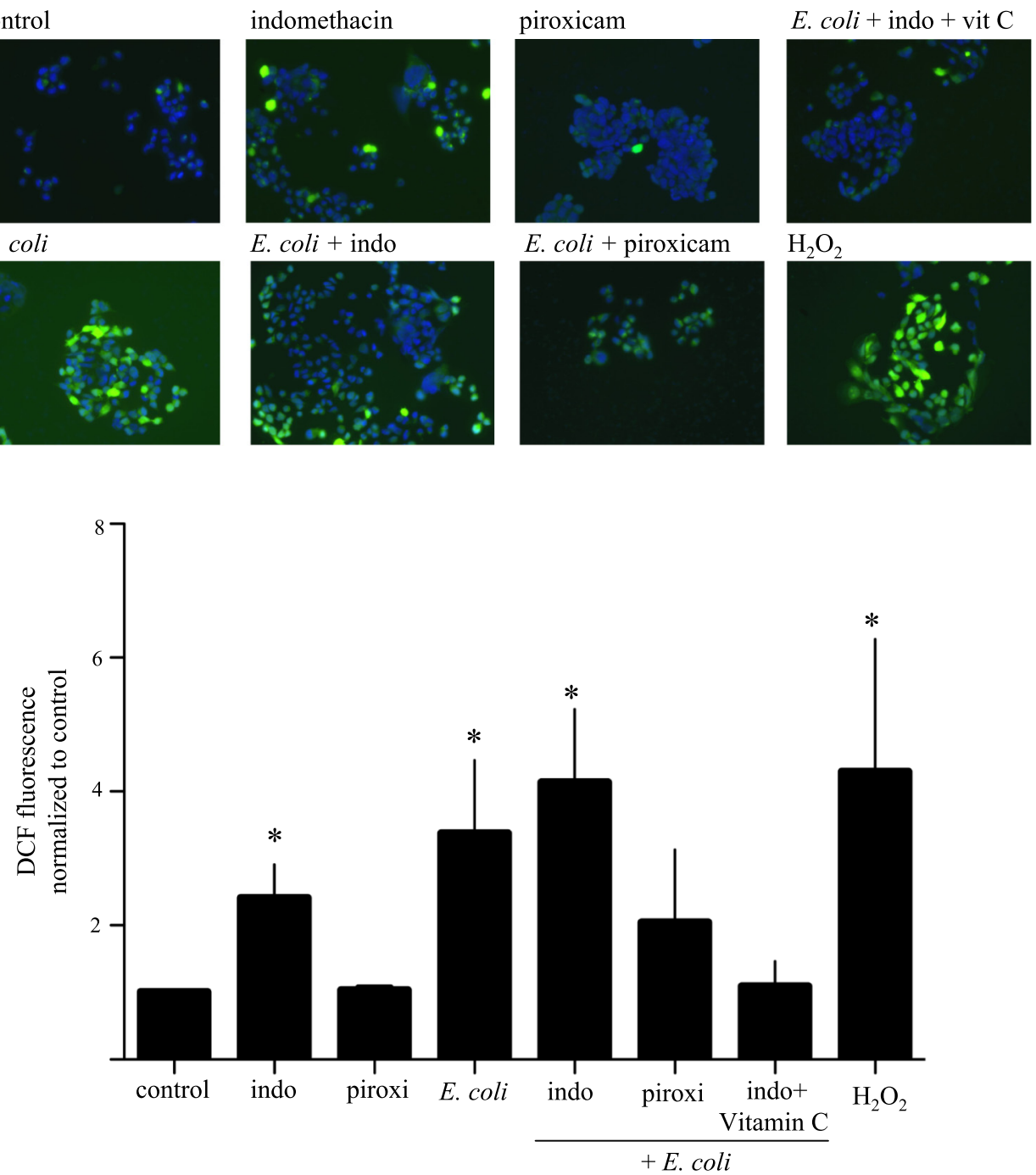


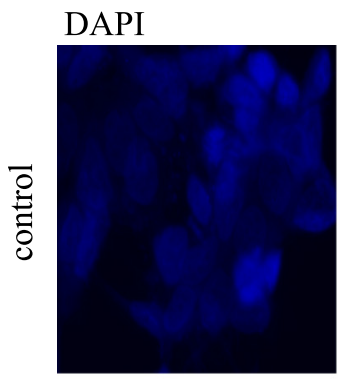

mitotracker
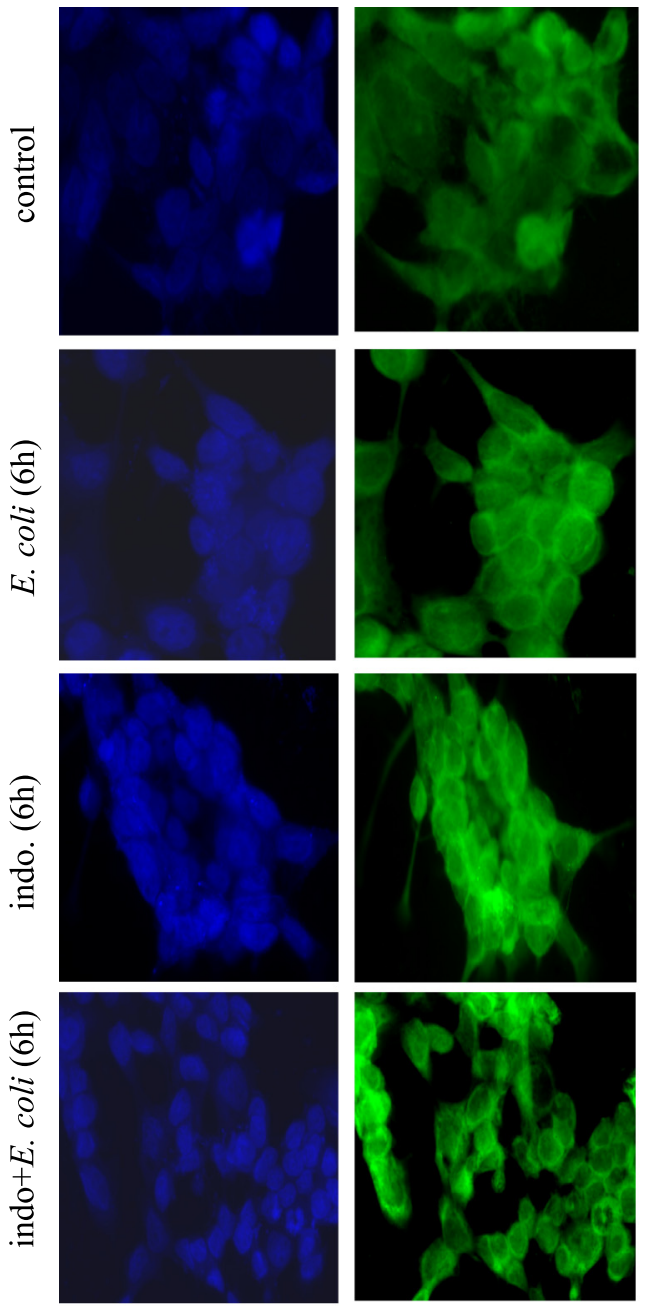

mitosox

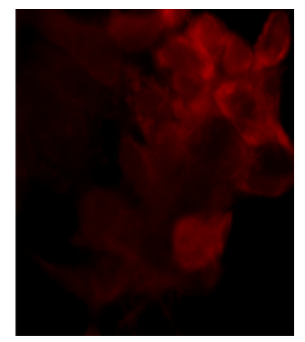

merge
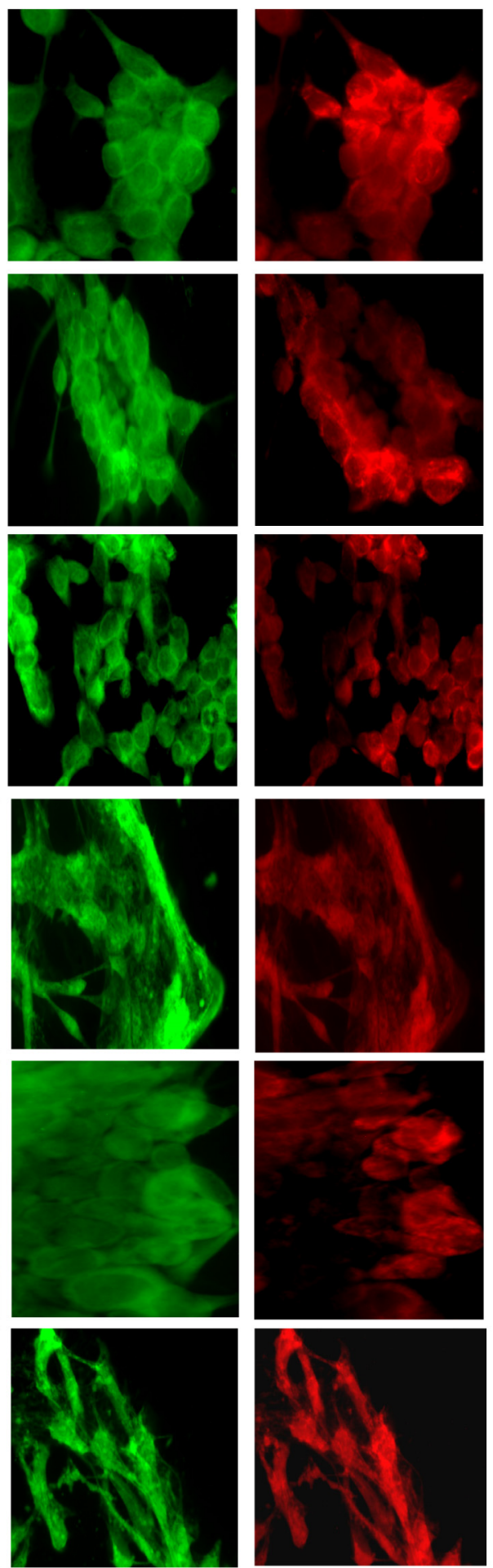
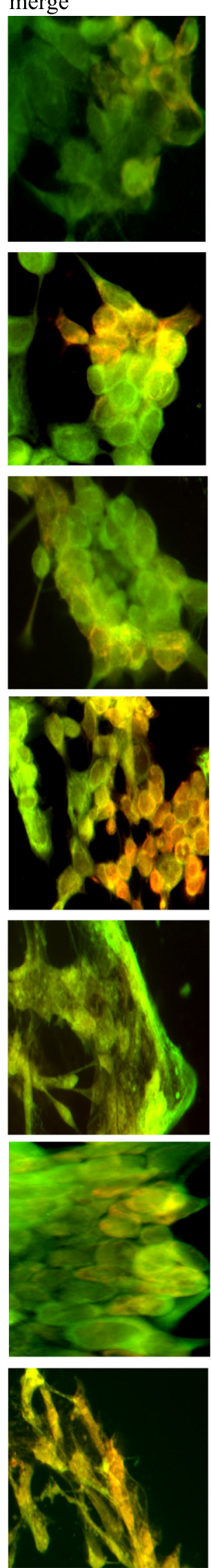

Fig. 5. Indomethacin induces enhanced mitochondria-derived superoxide production. Nature and source of the enhanced ROS production were determined 6 and $16 \mathrm{~h}$ posttreatment using MitoTracker Green (200 nM) for visualization of mitochondria and MitoSOX Red reagent $(5 \mu \mathrm{M})$ for detection of mitochondria-specific superoxide. Epithelial nuclei were identified by 4',6-diamidino-2-phenylindole (DAPI) staining. Confirming the generalized ROS production, T84 cells treated with $E$. coli $\left(10^{6} \mathrm{cfu}\right)$, indomethacin $(1 \mu \mathrm{M})$, or $E$. coli + indomethacin displayed increased MitoSOX Red reactivity, which was substantially increased at 6 and $16 \mathrm{~h}$ after E. coli + indomethacin treatment. Images are representative of 5-6 epithelial preparations from 2 separate experiments. 

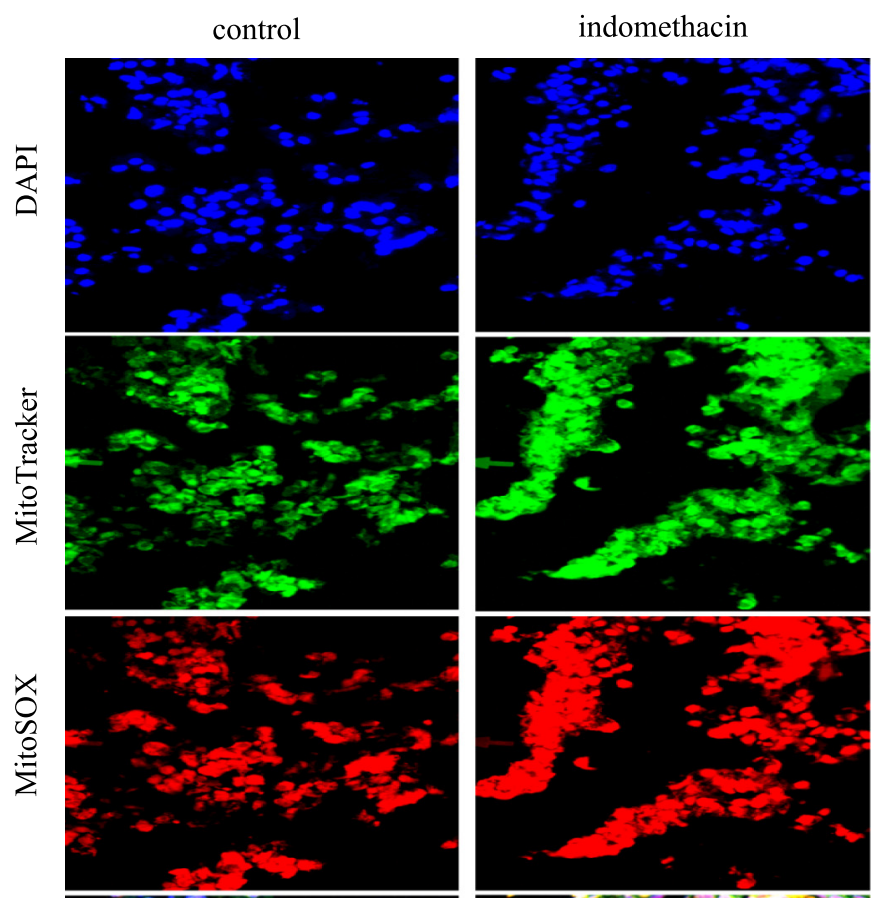

ఏ్ర
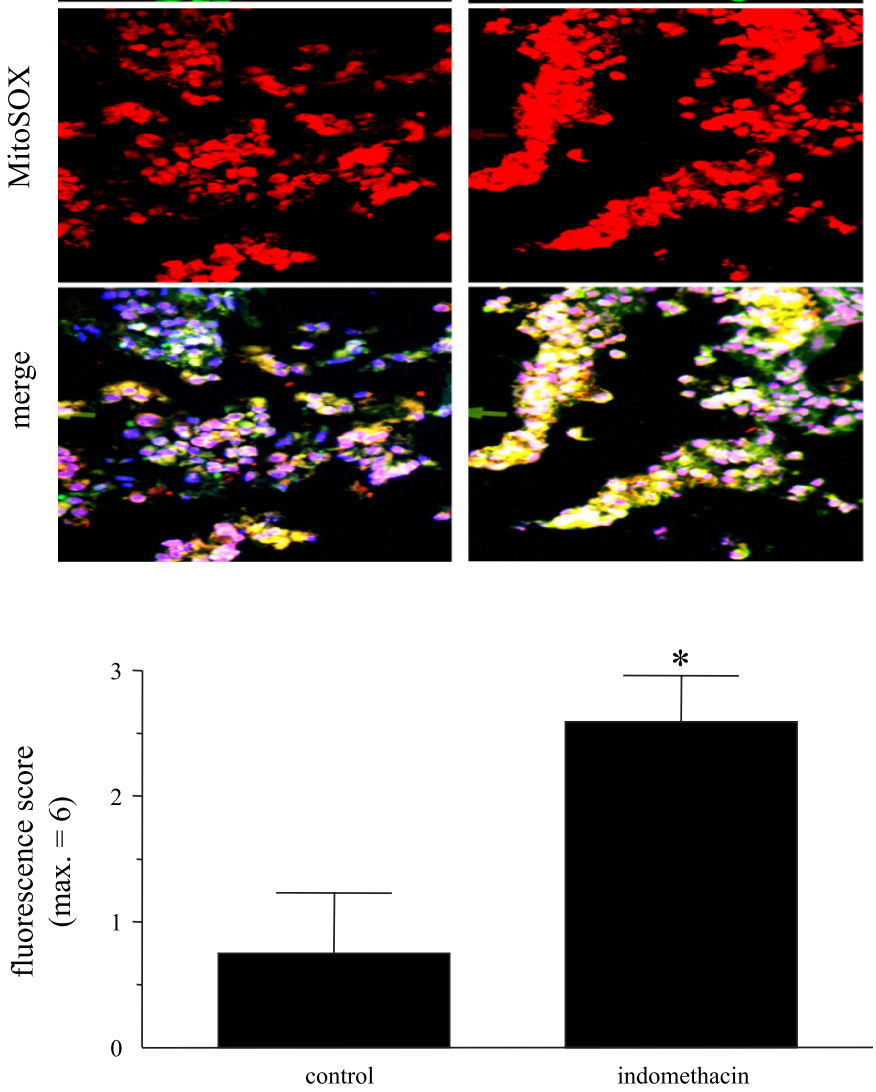

Fig. 6. Indomethacin induces increased mitochondria-derived superoxide production in whole tissue samples of murine duodenum. MitoTracker Green (200 $\mathrm{nM})$ and MitoSOX Red reagent $(5 \mu \mathrm{M})$ were used to detect and localize mitochondria-specific superoxide production, and nuclei were identified by DAPI $(0.2 \mu \mathrm{g} / \mathrm{ml})$ staining. Representative fluorescence images show increased superoxide detection in indomethacin-treated $(1 \mu \mathrm{M}, 6 \mathrm{~h})$ tissues. Images are representative of 2-4 tissue sections from 2 experiments. Semiquantitative analysis using an arbitrary fluorescence unit scale found this to be a statistically significant increase. Values are means $\pm \mathrm{SE} ; n=4$. ${ }^{*} P<0.05$ vs. control.

EGCG, which, among other properties, is a powerful antioxidant. The use of both agents significantly reduced the increase in bacterial internalization and translocation of bacteria across T84 cell monolayers (Fig. 7, A-C) caused by exposure to indomethacin $+E$. coli but was unable to ameliorate the drop in TER (Fig. 7D).

\section{DISCUSSION}

Physician-prescribed and available over-the-counter NSAIDs are ingested daily by millions of people (11). While this class of drug effectively suppresses inflammation and pain, NSAIDs come at the well-known costs of gastric ulceration and enteropathy and can be fatal due to gastrointestinal bleeding. NSAID use in humans $(7,22)$ or administration to rodents $(4,16,43)$ has been repeatedly shown to increase enteric epithelial permeability, and given the role that the epithelial barrier plays in holding the myriad of luminal antigens and microbes at bay $(12,13,43)$, it is not surprising that NSAIDs can initiate or reactivate intestinal disease $(5,28,39,42,51)$. Indomethacin has been widely used to model NSAID-induced enteropathy (9, 16, 19); yet despite extensive research, the exact mechanism whereby indomethacin disrupts the epithelial barrier remains a subject of debate. Indomethacin-induced gastrointestinal lesions have been linked to the suppression of prostaglandin production (16, $43,47)$. This was widely accepted as the cause of NSAIDinduced enteropathy, and while there is little doubt that this is a major part of the problem, recent data implicate perturbed epithelial mitochondrial function (and oxidative stress due to ROS $)(6,26)$ in indomethacin-induced gastropathy and apoptosis. A role for mitochondria and, by inference, metabolic stress raises the possibly that nutritional management to combat metabolic stress (24) could offset some of the intestinal damage caused by NSAID use.

Employing monolayers of the T84 human crypt-like epithelial cell line $(14,24)$, we assessed the effect of NSAIDs on epithelial barrier function using noninvasive $E$. coli as the "permeability probe," since the passage of bacteria across the epithelium may be a critical component of inflammatory bowel disease (1). Corroborating earlier studies $(7,42)$, we show that indomethacin has a significant direct detrimental effect on the barrier function of enteric epithelium, enhancing the transcytosis of the noninvasive, nontoxigenic, nonpathogenic E. coli strain HB101 (used as commensal organisms). Given the drop in TER, a marker of paracellular permeability, it is difficult to unequivocally designate the route of bacterial transcytosis as transcellular or via the paracellular shunt pathway. However, the following data suggest that at least a portion of the bacteria cross the epithelium via a transcellular route: 1 ) indomethacin treatment results in a significant increase in intracellular $E$. coli; 2) a portion of the $E$. coli that are internalized by T84 epithelia can "escape" the enterocyte (i.e., not all the bacteria are killed); and 3) the drop in TER is very similar in epithelia treated with $E$. coli and $E$. coli + indomethacin, yet only the latter show a substantial increase in bacterial transcytosis. Extrapolation from these findings raises two key issues. 1) If indomethacin has the same direct effect on enterocytes in vivo, then a transcellular pathway could be a significant route of entry for luminal bacteria into the gut mucosa. In this context, our finding of indomethacin-induced superoxide generation in whole tissue segments ex vivo is noteworthy. This supposition is supported by studies showing that interferon- $\gamma$ (41), the inhibitor of oxidative phosphorylation, dinitrophenol (DNP) $(24,31)$, and Campylobacter jejuni (20) promote the internalization of bacteria into model gut epithelia in vitro. 2) The epithelial response to internalized commensal organisms is poorly understood and requires investigation, as it has impli- 

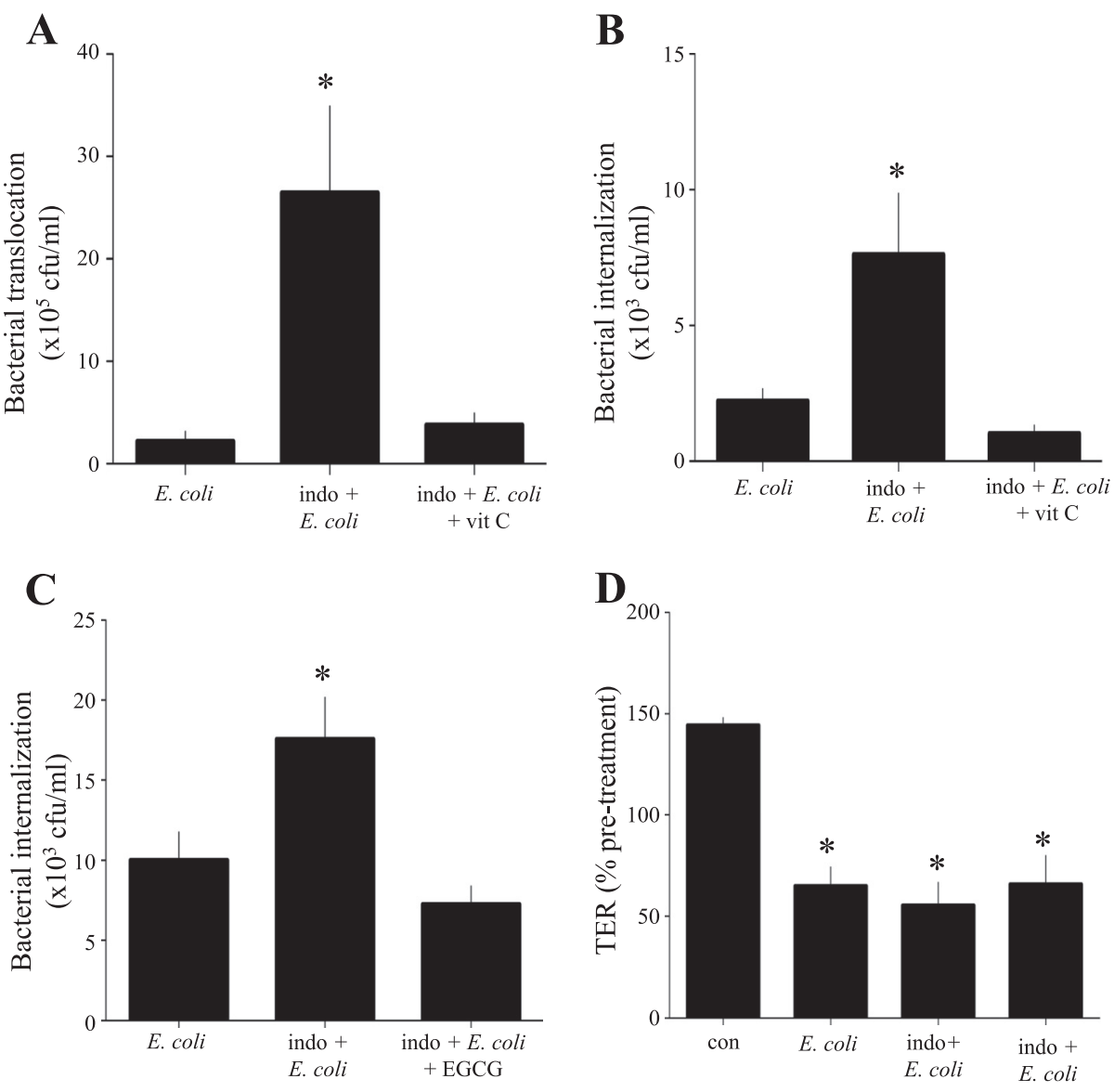

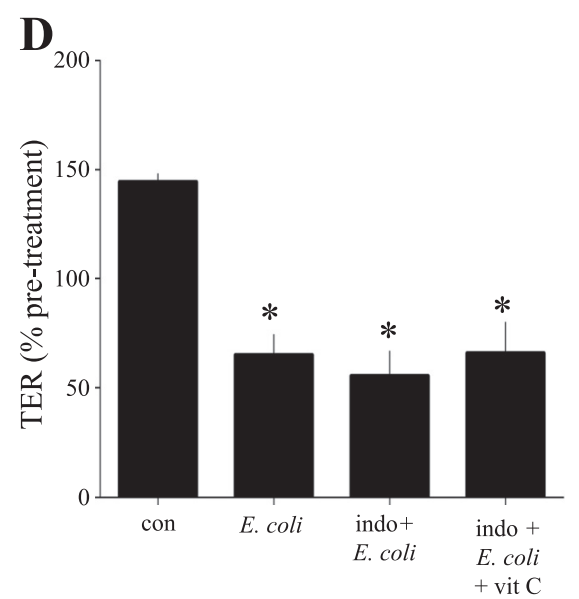

Fig. 7. Vitamin $\mathrm{C}$ blocks indomethacin-induced increases in bacterial translocation and internalization. $A$ : indomethacin-induced increase in bacterial translocation across T84 monolayers at $16 \mathrm{~h}$ posttreatment was ameliorated by cotreatment with vitamin $\mathrm{C}(0.25 \mathrm{mM})$, a potent ROS scavenger. Values are means \pm SE; $n=6$ epithelial preparations from 2 independent experiments. ${ }^{*} P<0.01$ vs. E. coli $\left(10^{6} \mathrm{cfu}\right)$ and indomethacin $(1 \mu \mathrm{M})+$ E. coli + vitamin C. $B$ and $C$ : vitamin $C(B)$ and the green tea extract epigallocathechin gallate (EGCG, $100 \mu \mathrm{M}$; $C$ ) inhibited epithelial internalization of $E$. coli evoked by indomethacin. Values are means $\pm \mathrm{SE} ; n=11$ epithelial preparations from 3 independent experiments. $* P<$ 0.05 vs. E. coli. $D$ : while significantly reducing bacterial internalization and transcytosis, vitamin $\mathrm{C}$ had no effect on the drop in TER caused by indomethacin $+E$. coli. Values are means $\pm \mathrm{SE}$; $n=7$ epithelial monolayers from 2 independent experiments. $* P<0.001$ vs. control (con). cations for epithelial-bacterial interactions and intestinal homeostasis.

Considering the mechanism of indomethacin-induced decreases in epithelial barrier function to bacteria, we did not observe similar events with piroxicam or SC-560, a COX-1/2 and a selective COX-1 inhibitor, respectively. While indomethacin and piroxicam are different classes of NSAIDs, both block prostaglandin synthesis by binding to the ATP pocket in the COX enzymes (34), and both have similar, but not identical, $\mathrm{IC}_{50}$ values for COX in in vitro assays (49), suggesting that inhibition of prostaglandin synthesis is not at the root of the direct effect of indomethacin on epithelial permeability. Furthermore, at equimolar doses, indomethacin is more ulcerogenic than piroxicam and is a more effective uncoupler of oxidative phosphorylation, suggesting that reduction of ATP and elevated levels of ROS are likely paramount in the indomethacin-induced increases in bacterial translocation and internalization (2). Epithelial apoptosis is another potential mechanism for the effect of indomethacin, but this is unlikely, as evidence of caspase- 3 cleavage and AIF mobilization was not forthcoming. Furthermore, while increased apoptosis would enhance bacterial translocation across an epithelial layer, it would not account for the increase in epithelial bacterial internalization observed here.

A number of reports on indomethacin-induced enteropathy have demonstrated a topical effect on the epithelium, a component of which was perturbed mitochondrial function $(4,6$, 26, 43). In accordance with these findings, using the MTT assay as a marker of mitochondrial activity, we found a slight reduction in mitochondrial function in T84 epithelia treated with indomethacin. Previous data show that metabolic stress induced by treatment of T84 cells with DNP is associated with reduced mitochondrial activity, which correlated with reduced expression of tight junction proteins $(24,30)$, and increased internalization and translocation of $E$. coli (31). Given the energy dependence of tight junction form and function and endocytotic processes (i.e., paracellular and transcellular permeability), reduced mitochondrial function would result in reduced ATP synthesis, thus contributing to the indomethacininduced epithelial barrier defect.

A more striking finding was the upregulation of ROS production in epithelial cells treated with $E$. coli alone or with indomethacin, and in the context of indomethacin, a substantial portion of the ROS could be attributed to mitochondrial production of superoxide. The direct ability of commensal bacteria to provoke epithelial ROS generation was initially surprising, but others reported similar data $(21,32,44)$. Moreover, the interface between the commensal flora and the colonic epithelium is important for normal physiology (e.g., vitamin and short-chain fatty acid absorption) and host defense: commensal flora that gain access to the systemic circulation can be lifethreatening $(1,10,12,13)$. Thus, ROS generation in response to commensal bacteria may be a means to regulate bacterial growth and may be important signaling molecules in the normal cross talk between the intestinal microbiota and the host. Indeed, short-term ( $\leq 30 \mathrm{~min}$ ) exposure of cultured co- 
lonic epithelial cells to human commensal E. coli elicited increased ROS production, which mediated degradation of IкB $\alpha$ and, hence, activation of NFкB (21). Increased bacterial translocation across DNP-treated epithelia was associated with Iк $\mathrm{B} \alpha$ phosphorylation (and, by implication, degradation) and was blocked by a panel of pharmacological inhibitors of NFKB activity (23).

Identification of pathophysiological mechanisms is only half of the problem; one must work toward intervention strategies that could reduce disease and restore digestive health. Given the slight drop in mitochondrial activity caused by indomethacin and the potential for ROS activity to be exaggerated by reduced production of endogenous antioxidants (e.g., the mitochondria-associated peroxiredoxin 3) and noting superoxide production by the mitochondria, we tested a role for ROS in the internalization and translocation of bacteria. Addition of vitamin C to the culture well, as expected, quenched the ROS, and this was accompanied by a reduction in indomethacin-evoked increases in $E$. coli internalization and translocation; a similar effect was observed with EGCG, although, in addition to its antioxidant properties, EGCG has been shown to block a number of intracellular signaling pathways, including $\mathrm{NF \kappa B}$ activation (25). These data corroborated recent findings showing that a polyphenol related to EGCG and present in apple peel inhibited indomethacin-induced mitochondrial dysfunction in cultured colonic epithelia (9).

A substantial body of data has been presented in favor of ROS as signaling mediators of autophagy, a process by which internalized bacterial products can be degraded (17). Recent findings have linked NSAID exposure to the induction of autophagy by showing that celecoxib induces increased expression of the autophagosomal protein LC3-II (18). Thus we speculate that one consequence of indomethacin-induced metabolic stress is an autophagy/survival program that results in the uptake of extracellular material. By extrapolation, the access of bacteria to the enterocyte and then the mucosa, if uncontrolled, could have pathophysiological consequences, and so the ability of vitamin $\mathrm{C}$ to block indomethacin-induced generation of ROS and the internalization and translocation of E. coli could be of therapeutic value.

We highlight the caveat that in vitro studies assessing the direct effect of indomethacin on epithelial cells cannot recapitulate NSAID-induced enteropathy. Thus the findings presented here should be complemented with a comprehensive in vivo rodent analysis using $\mathrm{COX}-1, \mathrm{COX}-2$, and $\mathrm{COX}-1 / 2$ knockout mice (and ideally with loss of these genes being restricted to the epithelium) and assessing gut permeability, bacterial translocation, and ROS generation. The summation of the in vitro and murine data could lead to translational studies in patients. Nevertheless, our studies show the potential for direct NSAID effects on the epithelium via mitochondriaderived ROS, but as elegantly defined by Wallace and colleagues $(33,48)$ and others $(35,50,52)$, NSAID-induced small bowel damage is a complex process, with maximum enteropathy requiring involvement of the commensal flora and enterohepatic recirculation of the NSAID.

In conclusion, we show that indomethacin, but not piroxicam or SC-560, directly affects epithelial barrier function, promoting the internalization and translocation of noninvasive $E$. coli across the epithelial layer. This effect of indomethacin is not likely due to its inhibition of COX activity but, rather, is linked to perturbation of mitochondrial activity and, specifically, ROS production. Finally, the data from this model system suggest that antioxidants, and possibly those targeted directly at the mitochondria (29), could be tested as an adjunct therapy along with NSAIDs, allowing the latter to exert their potent anti-inflammatory activity while potentially limiting the unwanted side effect of increased epithelial permeability as gauged by bacterial transcytosis.

\section{ACKNOWLEDGMENTS}

We acknowledge E. Hoshivar, an M.Sc. student (2009-2011) under the supervision and direction of D. M. McKay who conducted some experiments in this area (data not included).

\section{GRANTS}

D. M. McKay is an Alberta Heritage Foundation for Medical Research (AHFMR) Scientist and recipient of a Canada Research Chair (Tier 1) in Intestinal Immunophysiology. This work was funded by Canadian Institutes of Health Research Operating Grant MOP-171492 to D. M. McKay.

\section{DISCLOSURES}

No conflicts of interest, financial or otherwise, are declared by the authors.

\section{AUTHOR CONTRIBUTIONS}

I.S., C.M.M., J.D.S., and D.M.M. are responsible for conception and design of the research; I.S., C.M.M., R.G., V.C.P., and A.W. performed the experiments; I.S., C.M.M., V.C.P., and A.W. analyzed the data; I.S. and J.D.S. interpreted the results of the experiments; I.S. and C.M.M. prepared the figures; I.S. and D.M.M. drafted the manuscript; I.S., C.M.M., R.G., J.D.S., and D.M.M. edited and revised the manuscript; I.S., C.M.M., R.G., V.C.P., A.W., J.D.S., and D.M.M. approved the final version of the manuscript.

\section{REFERENCES}

1. Abraham C, Medzhitov R. Interactions between the host innate immune system and microbes in inflammatory bowel disease. Gastroenterology 140: 1729-1737, 2011.

2. Aguwa CN. Incidence of gastric ulcers by indomethacin and piroxicam in rats. Arch Toxicol 56: 212-213, 1985.

3. Baregamian N, Song J, Bailey CE, Papaconstantinou J, Evers BM, Chung DH. Tumor necrosis factor- $\alpha$ and apoptosis signal-regulating kinase 1 control reactive oxygen species release, mitochondrial autophagy, and c-Jun N-terminal kinase/p38 phosphorylation during necrotizing enterocolitis. Oxid Med Cell Longev 2: 297-306, 2009.

4. Basivireddy J, Vasudevan A, Jacob M, Balasubramanian KA. Indomethacin-induced mitochondrial dysfunction and oxidative stress in villus enterocytes. Biochem Pharmacol 64: 339-349, 2002.

5. Bernstein CN, Singh S, Graff LA, Walker JR, Miller N, Cheang M. A prospective population-based study of triggers of symptomatic flares in IBD. Am J Gastroenterol 105: 1994-2000, 2010.

6. Bindu S, Pal C, Dey S, Goyal M, Alam A, Iqbal MS, Dutta S, Sarkar S, Kumar R, Maity P, Bandyopadhyay U. Translocation of heme oxygenase-1 to mitochondria is a novel cytoprotective mechanism against non-steroidal anti-inflammatory drug-induced mitochondrial oxidative stress, apoptosis, and gastric mucosal injury. J Biol Chem 286: 3938739402, 2011.

7. Bjarnason I, Williams P, Smethurst P, Peters TJ, Levi AJ. Effect of non-steroidal anti-inflammatory drugs and prostaglandins on the permeability of the human small intestine. Gut 27: 1292-1297, 1986.

8. Carneiro LA, Travassos LH, Soares F, Tattoli I, Magalhaes JG, Bozza MT, Plotkowski MC, Sansonetti PJ, Molkentin JD, Philpott DJ, Girardin SE. Shigella induces mitochondrial dysfunction and cell death in nonmyleoid cells. Cell Host Microbe 5: 123-136, 2009.

9. Carrasco-Pozo C, Gotteland M, Speisky H. Apple peel polyphenol extract protects against indomethacin-induced damage in Caco-2 cells by preventing mitochondrial complex I inhibition. J Agric Food Chem 59: 11501-11508, 2011.

10. Chung H, Kasper DL. Microbiota-stimulated immune mechanisms to maintain gut homeostasis. Curr Opin Immunol 22: 455-460, 2010. 
11. Dai C, Stafford RS, Alexander GC. National trends in cyclooxygenase-2 inhibitor use since market release: nonselective diffusion of a selectively cost-effective innovation. Arch Intern Med 165: 171-177, 2005.

12. De-Souza DA, Greene LJ. Intestinal permeability and systemic infections in critically ill patients: effect of glutamine. Crit Care Med 33: 1125-1135, 2005.

13. Deitch EA, Xu D, Kaise VL. Role of the gut in the development of injuryand shock-induced SIRS and MODS: the gut-lymph hypothesis, a review. Front Biosci 11: 520-528, 2006.

14. Donato RP, El-Merhibi A, Gundsambuu B, Mak KY, Formosa ER, Wang X, Abbott CA, Powell BC. Studying permeability in a commonly used epithelial cell line: T84 intestinal epithelial cells. Methods Mol Biol 763: 115-137, 2011 .

15. Fellows IW, Bhaskar NK, Hawkey CJ. Nature and time-course of piroxicam-induced injury to human gastric mucosa. Aliment Pharmacol Ther 3: 481-488, 1989.

16. Hotz-Behofsits C, Simpson RJ, Walley M, Bjarnason IT. Role of COX-2 in nonsteroidal anti-inflammatory drug enteropathy in rodents. Scand J Gastroenterol 45: 822-827, 2010.

17. Huang J, Lam GY, Brumell JH. Autophagy signaling through reactive oxygen species. Antioxid Redox Signal 14: 2215-2231, 2011.

18. Huang S, Sinicrope FA. Celecoxib-induced apoptosis is enhanced by ABT-737 and by inhibition of autophagy in human colorectal cancer cells. Autophagy 6: 256-269, 2010.

19. Jacob M, Bjarnason I, Rafi S, Wrigglesworth J, Simpson RJ. A study of the effects of indomethacin on liver mitochondria from rats, mice and humans. Aliment Pharmacol Ther 15: 1837-1842, 2001.

20. Kalischuk LD, Inglis GD, Buret AG. Campylobacter jejuni induces transcellular translocation of commensal bacteria via lipid rafts. Gut Pathog 1: 2, 2009.

21. Kumar A, Wu H, Collier-Hyams LS, Hansen JM, Li T, Yamoah K, Pan ZQ, Jones DP, Neish AS. Commensal bacteria modulate cullindependent signaling via generation of reactive oxygen species. EMBO J 26: 4457-4466, 2007.

22. Lanas A. A review of the gastrointestinal safety data-a gastroenterologist's perspective. Rheumatology 49 Suppl 2: II3-II10, 2010.

23. Lewis K, Caldwell J, Phan V, Prescott D, Nazli A, Wang A, Soderholm JD, Perdue MH, Sherman PM, McKay DM. Decreased epithelial barrier function evoked by exposure to metabolic stress and nonpathogenic E. coli is enhanced by TNF- $\alpha$. Am J Physiol Gastrointest Liver Physiol 294: G669-G678, 2008

24. Lewis K, Lutgendorff F, Phan V, Soderholm JD, Sherman PM, McKay DM. Enhanced translocation of bacteria across metabolically stressed epithelia is reduced by butyrate. Inflamm Bowel Dis 16: $1138-$ 1148, 2010.

25. Lin JK, Liang YC, Lin-Shiau SY. Cancer chemoprevention by tea polyphenols through mitotic signal transduction blockade. Biochem Pharmacol 58: 911-915, 1999.

26. Maity P, Bindu S, Dey S, Goyal M, Alam A, Pal C, Mitra K, Bandyopadhyay U. Indomethacin, a non-steroidal anti-inflammatory drug, develops gastropathy by inducing reactive oxygen species-mediated mitochondrial pathology and associated apoptosis in gastric mucosa: a novel role of mitochondrial aconitase oxidation. J Biol Chem 284: $3058-$ 3068, 2009.

27. Massaad CA, Washington TM, Pautler RG, Klann E. Overexpression of SOD-2 reduces hippocampal superoxide and prevents memory deficits in a mouse model of Alzheimer's disease. Proc Natl Acad Sci USA 106: 13576-13581, 2009.

28. May GR, Sutherland LR, Meddings JB. Is small intestinal permeability really increased in relatives of patients with Crohn's disease? Gastroenterology 104: 1627-1632, 1993.

29. McManus MJ, Murphy MP, Franklin JL. The mitochondria-targeted antioxidant MitoQ prevents loss of spatial memory retention and early neuropathology in a transgenic mouse model of Alzheimer's disease. $J$ Neurosci 31: 15703-15715, 2011.

30. Nazli A, Wang A, Steen O, Prescott D, Lu J, Perdue MH, Soderholm JD, Sherman PM, McKay DM. Enterocyte cytoskeleton changes are crucial for enhanced translocation of nonpathogenic Escherichia coli across metabolically stressed gut epithelia. Infect Immun 74: 192-201, 2006.

31. Nazli A, Yang PC, Jury J, Howe K, Watson JL, Soderholm JD, Sherman PM, Perdue MH, McKay DM. Epithelia under metabolic stress perceive commensal bacteria as a threat. Am J Pathol 164: 947-957, 2004.
32. Neish AS, Gewirtz AT, Zeng H, Young AN, Hobert ME, Karmali V, Rao AS, Madara JL. Prokaryotic regulation of epithelial responses by inhibition of IкB- $\alpha$ ubiquitination. Science 289: 1560-1563, 2000.

33. Reuter BK, Davis NM, Wallace JL. Nonsteroidal anti-inflammatory drug enteropathy in rats: role of permeability, bacteria and enterohepatic circulation. Gastroenterology 112: 109-110, 1997.

34. Riendeau D, Percival MD, Boyce S, Brideau C, Charleson S, Cromlish W, Ethier D, Evans J, Falgueyret JP, Ford-Hutchinson AW, Gordon R, Greig G, Gresser M, Guay J, Kargman S, Leger S, Mancini JA, O'Neill G, Ouellet M, Rodger IW, Therien M, Wang Z, Webb JK, Wong E, Xu L, Young RN, Zamboni R, Prasit P, Chan CC. Biochemical and pharmacological profile of a tetrasubstituted furanone as a highly selective COX-2 inhibitor. Br J Pharmacol 121: 105-117, 1997.

35. Robert A, Asano T. Resistance of germ-free rats to indomethacin-induced lesions. Prostaglandins 14: 331-341, 1977.

36. Roth SH. Nonsteroidal anti-inflammatory drug gastropathy: new avenues for safety. Clin Interv Aging 6: 125-131, 2011

37. Rowlinson SW, Kiefer JR, Prusakiewicz JJ, Pawlitz JL, Kozak KR, Kalgutkart AS, Stallings WC, Kurumbail RG, Marnett LJ. A novel mechanism of cyclooxygenase-2 inhibition involving interactions with Ser-530 and Tyr-385. J Biol Chem 278: 45763-45769, 2003.

38. Salim SY, Soderholm JD. Importance of disrupted intestinal barrier in inflammatory bowel diseases. Inflamm Bowel Dis 17: 362-381, 2011.

39. Samadder NJ, Mukherjee B, Huang SC, Ahn J, Rennert HS, Greenson JK, Rennert G, Gruber SB. Risk of colorectal cancer in self-reported inflammatory bowel disease and modification of risk by statin and NSAID use. Cancer 117: 1640-1648, 2011.

40. Schoultz I, Soderholm JD, McKay DM. Is metabolic stress a common denominator in inflammatory bowel disease? Inflamm Bowel Dis 17: 2008-2018, 2011.

41. Smyth D, Phan V, Wang A, McKay DM. Interferon- $\gamma$-induced increases in intestinal epithelial macromolecular permeability requires the Src kinase Fyn. Lab Invest 91: 764-777, 2011.

42. Soderholm JD, Olaison G, Lindberg E, Hannestad U, Vindels A, Tysk C, Jarnerot G, Sjodahl R. Different intestinal permeability patterns in relatives and spouses of patients with Crohn's disease: an inherited defect in mucosal defence? Gut 44: 96-100, 1999.

43. Somasundaram S, Sigthorsson G, Simpson RJ, Watts J, Jacob M, Tavares IA, Rafi S, Roseth A, Foster R, Price AB, Wrigglesworth JM, Bjarnason I. Uncoupling of intestinal mitochondrial oxidative phosphorylation and inhibition of cyclooxygenase are required for the development of NSAID-enteropathy in the rat. Aliment Pharmacol Ther 14: 639-650, 2000.

44. Swanson PA, Kumar A, Samarin S, Vijay-Kumar M, Kundu K, Murthy N, Hansen J, Nusrat A, Neish AS. Enteric commensal bacteria potentiate epithelial restitution via reactive oxygen species-mediated inactivation of focal adhesion kinase phosphatases. Proc Natl Acad Sci USA 108: 8803-8808, 2011.

45. Tomisato W, Tsutsumi S, Hoshino T, Hwang HJ, Mio M, Tsuchiya T, Mizushima T. Role of direct cytotoxic effects of NSAIDs in the induction of gastric lesions. Biochem Pharmacol 67: 575-585, 2004.

46. Turner JR. Intestinal mucosal barrier function in health and disease. Nat Rev Immunol 9: 799-809, 2009.

47. Wallace JL. Prostaglandins, NSAIDs and gastric mucosal protection: why doesn't the stomach digest itself? Physiol Rev 88: 1547-1565, 2008.

48. Wallace JL, Syer S, Denou E, De Palma G, Vong L, McNight W, Jury J, Bolla M, Bercik P, Collins SM, Verdu E, Ongini. Proton pump inhibitors exacerbate NSAID-induced small intestinal injury by inducing dysbiosis. Gastroenterology 141: 1314-1322, 2011.

49. Warner TD, Giuliano F, Vojnovic I, Bukasa A, Mitchell JA, Vane JR. Nonsteroidal drug selectivities for cyclo-oxygenase-1 rather than cyclooxygenase-2 are associated with human gastrointestinal toxicity: a full in vitro analysis. Proc Natl Acad Sci USA 96: 7563-7568, 1999.

50. Watanabe T, Higuchi K, Kobata H, Nishio H, Tanigawa T, Shiba M, Tominaga K, Fujiwara Y, Oshitani N, Asahara T, Nomoto K, Takeuchi K, Arakawa T. Non-steroidal anti-inflammatory drug-induced small intestinal damage is Toll-like receptor 4 dependent. Gut 57: 181-187, 2008.

51. Zamora SA, Hilsden RJ, Meddings JB, Butzner JD, Scott RB, Sutherland LR. Intestinal permeability before and after ibuprofen in families of children with Crohn's disease. Can J Gastroenterol 13: 31-36, 1999.

52. Zhou Y, Dial EJ, Doyen R, Lichtenberger LM. Effect of indomethacin on bile acid-phospholipid interactions: implication for small intestinal injury induced by nonsteroidal anti-inflammatory drugs. Am J Physiol Gastrointest Liver Physiol 298: G722-G731, 2010. 